\title{
Avaliação da atividade angiogênica da solução aquosa do barbatimão (Stryphnodendron adstringens)
}

CHAVES, D.A.'; LEMES, S.R.2; ARAUJO, L.A.2; SOUSA, M.A.M.';FREITAS, G.B.'; LINO-JUNIOR, R.S. ${ }^{2}$; MRUE, F.'; MELO-REIS, P.R.'.

${ }^{\top}$ Pontifícia Universidade Católica de Goiás, Laboratório de Estudos Experimentais e Biotecnológicos, Rua 232, no 128, $3^{\circ}$ andar, Goiânia-GO, Brasil, CEP 74605-140. 2Universidade Federal de Goiás- UFG, Av. Esperança, s/n - Setor Itatiaia, Campus Samambaia, Goiânia-GO, Brasil, CEP 74690-900. Universidade Federal de Goiás. Instituto de Patologia Tropica e Saúde Pública. Laboratório de Patologia Experimental., Rua 235 S/N, Setor Universitário, Goiânia - Goiás. *Autor para correspondência: susy_nzr@gmail.com

RESUMO: O Barbatimão (Stryphnodendron adstringens) planta medicinal encontrada no bioma Cerrado apresenta propriedades físico-químicas que lhe garante importantes atividades farmacológicas tais como: anti-inflamatória, analgésica e uma atividade protetora da mucosa gástrica. A casca do tronco é a principal matéria-prima usada para o desenvolvimento de produtos medicinais. Neste estudo, o objetivo foi investigar a influência da solução aquosa da casca do barbatimão no processo de formação de vasos sanguíneos na membrana corioalontoide de ovo embrionado de galinha. Foram utilizadas $30 \mathrm{~g}$ da casca triturada em um litro de água. Este processo permitiu a obtenção da Solução Aquosa de Barbatimão - SAB em uma concentração de $30 \mathrm{mg} / \mathrm{mL}$. A atividade angiogênica da solução aquosa do barbatimão foi avaliada mediante realização de testes laboratoriais "in vivo", utilizando como modelo experimental a membrana do ovo embrionado de galinha (MCA). Utilizou-se como controle indutor o Regederm $®$, o qual apresenta atividade angiogênica conhecida. Os resultados demonstraram que a SAB apresentou um percentual de vascularização na MCA de $(50.4 \%)$ não tendo diferença $(p>0,05)$ aos valores detectados no controle indutor (52,9\%). Com os resultados obtidos, percebe-se que o barbatimão apresenta atividade angiogênica no modelo experimental utilizado.

Palavras chave: Angiogênese, barbatimão, membrana, ovo.

\begin{abstract}
Angiogenic activity of the aqueous solution of Barbatimão (Stryphnodendron adstringens). The Barbatimão (Stryphnodendron adstringens) medicinal plant found in the Cerrado biome has physicochemical properties which guarantee important pharmacological activities such as anti-inflammatic, analgesic and protective activities of gastric mucosa. The bark of the trunk is the main raw material used for the development of medicinal products. In this study, the objective was to investigate the influence of the aqueous solution of barbatimão bark in the formation of blood vessels in the membrane of embryonated chicken egg corioalontoid. $30 \mathrm{~g}$ of shredded bark was used in one liter of water. This process enabled the obtention of aqueous Barbatimão - BSA at a concentration of $30 \mathrm{mg} / \mathrm{ml}$. The angiogenic activity of the aqueous solution of barbatimão was assessed by laboratory testing "in vivo", using the chorioallantoic membrane of embryonated chicken egg (MCA) as an experimental model. TheRegederm ${ }^{\circledR}$ controlinductor was used, which exhibits known angiogenic activity. The results showed that the percentage of BSA showed a vascularization of the MCA $(50.4 \%)$ there was no difference $(p>0.05)$ in the values detected in the control inductor (52.9\%). With the obtained results, it is clear that barbatimão shows angiogenic activity under the experimental model used.
\end{abstract}

Key words: Angiogenesis, barbatimão, membrane, egg. 


\section{INTRODUÇÃO}

O processo de angiogênese é definido como a formação de novos vasos sanguíneos por um processo de germinação de brotos endoteliais a partir de vasos capilares preexistentes (Hanahan \& Folkman, 1996). Este evento está relacionado a vários processos fisiológicos, incluindo: a menstruação, ovulação, formação do corpo lúteo, nidação, morfogênese, cicatrização de feridas. Além disso, a angiogênese esta envolvida em processos patológicos como artropatias crônicas, inflamação crônica, psoríase, retinopatia diabética, angiofibroma, hemangioma, glaucoma vascular, crescimento tumoral, disseminação metastática e desenvolvimento de placa de ateroma (Hanahan \& Folkman, 1996; Vile, 1995; Folkman, 1971, 1976; Van Der Schaft et al., 1993; Johnson, 2001; Blaauwgeers et al., 1999).

Folkman, em 1971, sugeriu que o controle da angiogênese poderia ser útil no controle do crescimento tumoral. A desregulação na angiogênese está associada ao crescimento de tumores e a doenças angioproliferativas. No entanto, o estímulo farmacológico da angiogênese pode ser benéfico em situações clínicas na qual sua ativação é terapeuticamente necessária, tais como na reparação de feridas e na isquemia (Detillieux et al., 2003).

Neste sentido, existem relatos na literatura sobre determinados produtos de origem vegetal que apresentam substâncias indutoras de angiogênese (Wang et al., 2004). Atualmente, já é possível observar a existência de inúmeros fármacos com a capacidade de promover a angiogênese. Entre estes, destacam-se cremes que induzem a cicatrização de feridas, como exemplo: a Regederm® (Almeida et al., 2015).

O barbatimão apresentapropriedades medicinais e é popularmente empregado no tratamento de leucorreia, diarreia, hemorragia, hemorroida, feridas, conjuntivite, inflamação da garganta, corrimento vaginal e úlcera gástrica (Silva et al., 2010).

Devido ao uso popular da solução aquosa do barbatimão para o tratamento de feridas da pele, torna-se necessária a investigação científica da atividade angiogênica dessa solução. Considerando a importância da descoberta de novas substâncias que induzem a formação de novos vasos sanguíneos, o presente estudo teve como objetivo de avaliar a atividade angiogênica da solução aquosa do barbatimão (Stryphnodendron adstringens), mediante realização de testes laboratoriais "in vivo", utilizando como modelo experimental a membrana corioalantóide do ovo embrionado de galinha.

\section{MATERIAL E MÉTODO} (SAB)

\section{Solução aquosa da casca do barbatimão}

30 gramas da casca do barbatimão (adquiridas no comércio especializado da cidade de Goiânia-GO) foram trituradas em liquidificador industrial e adicionados $1.000 \mathrm{~mL}$ de água destilada. A solução obtida apresentou concentração de 30 $\mathrm{mg} / \mathrm{mL}$.

A atividade angiogênica da solução aquosa do barbatimão foi avaliada mediante realização de testes laboratoriais "in vivo", utilizando como modelo experimental a membrana corioalantóide do ovo embrionado de galinha. Os experimentos foram desenvolvidos no Laboratório de Estudos Experimentais e Biotecnológicos (LEB), do Mestrado de Ciências Ambientais e Saúde (MCAS), da Pontifícia Universidade Católica de Goiás (PUCGoiás).

\section{Controles para o teste da MCA}

Foram analisadas 56 membranas corioalantóides (MCAs) de ovos embrionados de galinha (Gallus domesticus, linhagem Rhoss) distribuídas da seguinte maneira: 14 MCAs para o controle positivo (Regederm $\left.{ }^{\circledR}\right), 14$ para o controle negativo (Água destilada estéril), 14controle inibidor (Dexametasona à $4 \mathrm{mg} / \mathrm{mL}$ ) e 14 para a solução aquosa do barbatimão.

Procedimento experimental da angiogênese

Os ovos embrionados foram incubados em estufa automática a temperatura de $37^{\circ} \mathrm{C} \pm 1^{\circ} \mathrm{C}$, umidade relativa da estufa de $65 \%$ e deslocados lateralmente a cada 15 minutos, durante os cinco primeiros dias de incubação. No quinto dia, foi realizada, na casca do ovo, uma abertura circular (Figura 1 - A) com 1,0 cm de diâmetro em sua base maior (onde está localizada a câmara de ar) com auxílio de uma micro-retífica (Ribatti et al., 2001).

Após a realização da abertura na casca do ovo, foi depositada uma gota de soro fisiológico $(0,9 \%)$ na membrana da casca, a fim de auxiliar na exposição da MCA já vascularizada. No $13^{\circ}$ dia de incubação, discos de papel de filtro com $0,5 \mathrm{~cm}$ de diâmetro, veiculando $3 \mu \mathrm{L} /$ filtro da solução aquosa do barbatimão, controles negativo (água destilada estéril), inibidor (solução de dexametasona) e positivo (Regederm $\AA$ ) foram colocados diretamente sobre vasos da MCA. Todos os ovos voltaram para a incubação onde permaneceram até o $16^{\circ}$ dia (Figura 1 - B).

Os discos foram depositados diretamente sobre a membrana de forma cuidadosa. Todos 

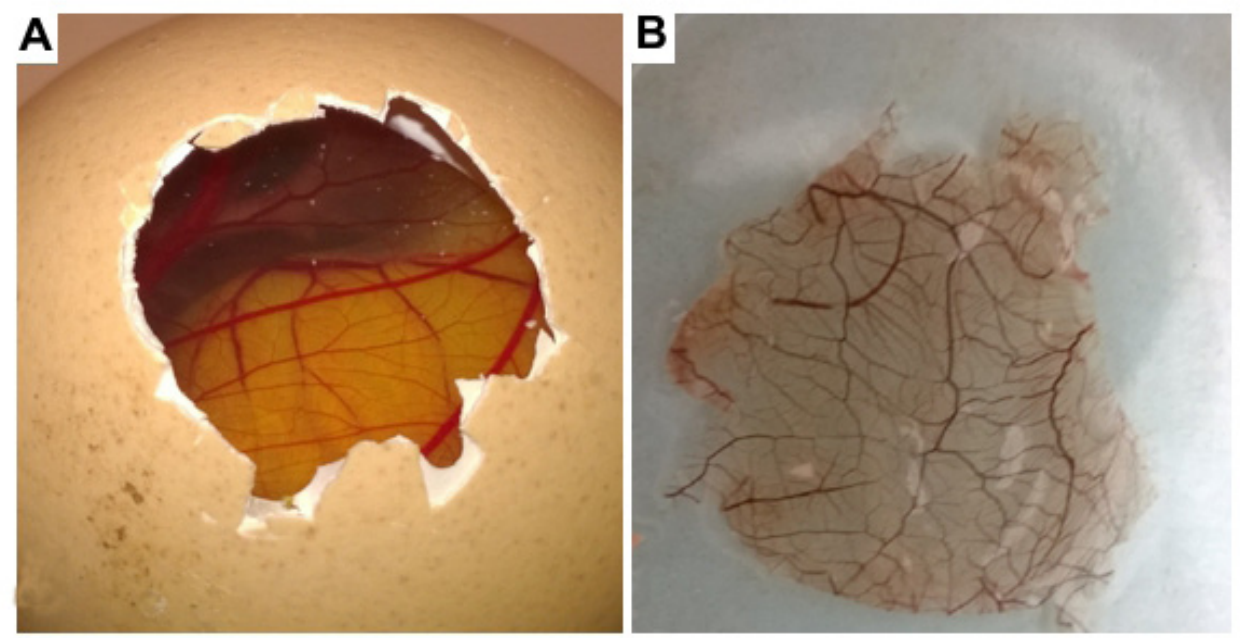

FIGURA 1. Visão da abertura realizada na casca do ovo embrionada e MCA obtida

A- Detalhes da abertura de $1,0 \mathrm{~cm}$ de diâmetro na casca do ovo, apresentação da CAM vascularizada. B- Visão da rede vascular da CAM no $16^{\circ}$ dia desenvolvimento da SAB.

os ovos voltaram para a incubação até o $16^{\circ}$ dia, quando então foram retirados da incubadora (Ribatti et al., 2001). As MCAs foram recortadas com tesoura cirúrgica e inseridas em placas de petri contendo solução formol a $10 \%$. Posteriormente foram obtidas imagens das MCAs com uso de uma câmera digital (12 megapixels).

As redes vasculares formadas nas MCAs foram quantificadas pelo processamento da imagem utilizando o programa de domínio público Gimp for Windows (versão 2.0.5) e Image J (versão 1.28) para visualização dos vasos sanguíneos (Wilting et al., 1991, Melo-Reis et al., 2010).

O processamento das imagens ocorreu de forma que a saturação, luz e contraste proporcionaram melhor resolução dos vasos sanguíneos e a quantificação em percentagem de área dos vasos sanguíneos formados (Mansur et al., 2006).

As áreas percentuais obtidas das MCAs dos grupos (teste e controles) foram armazenadas em um planilha de cálculo e posteriormente, receberam a análise estatística utilizando o software de domínio publico BioEstat 3.5. e depois comparados entre si.

Para avaliar a relação entre os dados dos grupos (teste e controles), utilizou o teste estatístico de Krushal-Wallis (Análise de variância-ANOVA). O valor de $p$ foi considerado significativo quando foi menor que 0,05 .

As análises histopatológicas as MCAs foram fixadas em formaldeído a $10 \%$, emblocadas em parafina, cortadas a $5 \mu \mathrm{m}$ e coradas pela técnica de Hematoxilina \& Eosina. Foram avaliadas as presenças de angiogênese e de elementos inflamatórios Melo-Reis et al., 2010; Araújo et al., 2015; Bessa et al., 2015).

\section{RESULTADOS}

Os resultados obtidos da porcentagem de vascularização na CAM da solução aquosa do barbatimão juntamente com os controles indutor, inibidor e negativo estão apresentados na Tabela 1.

Observou-se que a solução aquosa de barbatimão apresentou aumento da percentagem no número de vasos formados (atividade angiogênica) em relação aos controles negativo $(p<0,05)$ e inibidor $(p<0,05)$ (Figura 2 e Figura 3$)$. Entretanto, não foram constatadas diferenças no percentual rede vascular (Figura 1) obtido nas amostras tratadas com a solução aquosa do barbatimão e o controle positivo $(p>0,05)$. Observou-se também que 0 controle a solução de dexametasona apresentou significativa redução da vascularização da MCA em relação ao controle negativo $(p<0,05)$. As imagens apresentadas na figura 2 mostram a formação da rede vascular nos controles e no tratamento com solução aquosa de barbatimão.

\section{Análises histológicas}

As imagens da análise histológica são apresentadas na (Figura 4). A figura apresenta uma formação de rede vascular em diferentes grupos controles (inibidor e indutor) e no grupo do tratamento com a solução aquosa do barbatimão.

Observa-se a presença de tecido conjuntivo, elementos inflamatórios e vasos sanguíneos bem formados que exibem na luz vascular eritroblastos (Figura 5).

\section{DISCUSSÃO}

Não foram encontrados estudos envolvendo atividade angiogênica e barbatimão. Desta forma, este estudo poderá fornecer subsídio para pesquisas futuras, tendo em vista o interesse do Ministério da 
TABELA 1. Avalição percentual da rede vascular formada na MCA após tratamento da solução aquosa de barbatimão e controles (Indutor, Negativo e Inibidor).

\begin{tabular}{ccccc}
\hline $\begin{array}{c}\text { Identificação numé- } \\
\text { rica das CAM's }\end{array}$ & $\begin{array}{c}\text { Controle Indutor - } \\
\text { Regederm }\end{array}$ & $\begin{array}{c}\text { Controle Negativo } \\
\mathbf{H}_{\mathbf{2}} \mathbf{O}\end{array}$ & $\begin{array}{c}\text { Controle inibidor } \\
\text { Dexametasona }\end{array}$ & $\begin{array}{c}\text { S.A de } \\
\text { Barbatimão }\end{array}$ \\
\hline 1 & 49,6 & 33,4 & 9,6 & 51,3 \\
2 & 52,2 & 32,1 & 15,3 & 54,7 \\
3 & 56,5 & 40,1 & 14,8 & 50,2 \\
4 & 59,4 & 33,9 & 12,8 & 49,5 \\
5 & 55,6 & 29,4 & 11,5 & 45,1 \\
6 & 52,5 & 37,6 & 11,9 & 48,2 \\
7 & 60,1 & 28,3 & 10,8 & 47,4 \\
8 & 54,9 & 35,9 & 14,2 & 52,8 \\
9 & 56,4 & 32,3 & 10,2 & 50,9 \\
10 & 48,5 & 30,7 & 11,9 & 51,7 \\
11 & 48,6 & 29,4 & 14,5 & 50,9 \\
12 & 48,9 & 29,3 & 12,1 & 49,7 \\
13 & 50,2 & 32,1 & 11,3 & 48,9 \\
14 & 47,2 & 36,2 & 9,2 & 54,3 \\
\hline Média & $\mathbf{5 2 , 9} \%$ & $\mathbf{3 2 , 9 \%}$ & $\mathbf{1 2 , 2} \%$ & $\mathbf{1 0 , 4} \%$ \\
DP* & $\mathbf{4 , 2}$ & $\mathbf{3 , 5}$ & & $\mathbf{2 , 6}$ \\
\hline
\end{tabular}

${ }^{*} \mathrm{DP}=$ Desvio Padrão
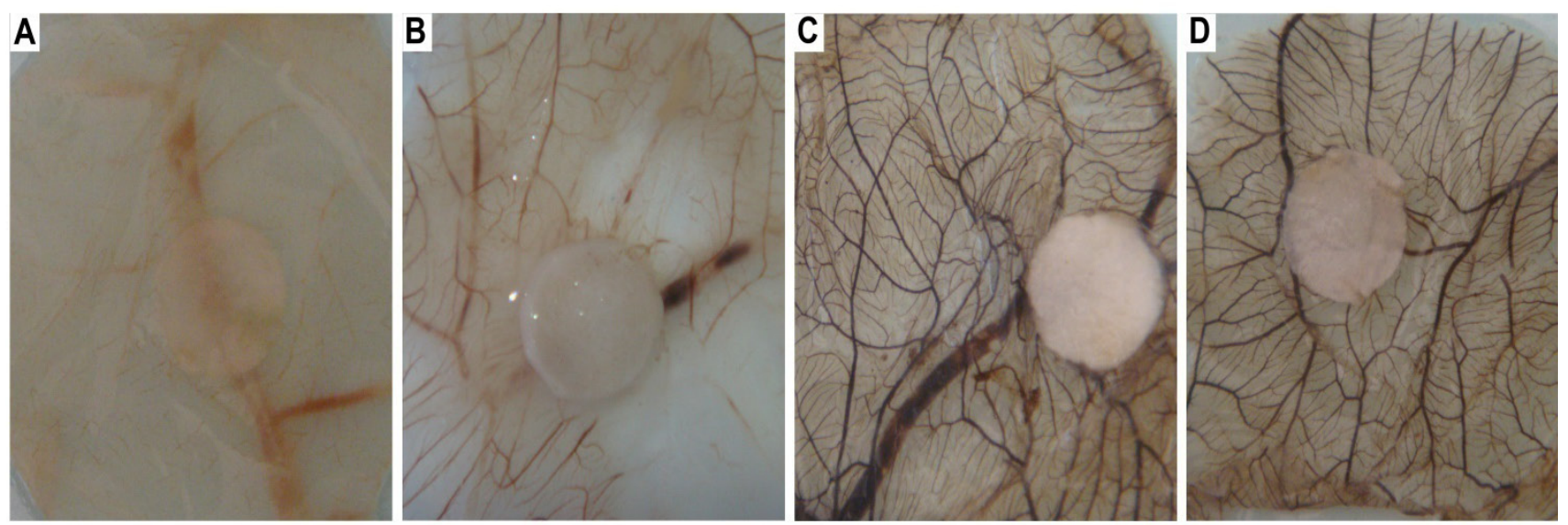

FIGURA 2. Fotomicrografia digital obtida da rede vascular formada na MCA após o tratamento, com solução aquosa de barbatimão juntamente com os controles.

A - Controle inibidor. B - Controle negativo. C - Controle indutor (Regederm). D - Teste (Solução aquosa do Barbatimão).

Saúde em plantas medicinais, pois o barbatimão faz parte da Relação Nacional de Plantas Medicinais de Interesse ao SUS (RENISUS). O RENISUS é o Programa Nacional de Plantas Medicinais e Fitoterápicos que tem como objetivos inserir, com segurança, eficácia e qualidade, plantas medicinais, fitoterápicos e serviços relacionados à Fitoterapia no SUS. (SUS, 2014).

Os resultados encontrados neste estudo indicaram que os testes realizados com a solução aquosa de barbatimão na concentração de 30 $\mathrm{mg} / \mathrm{mL}$ induziram a formação de novos vasos sanguíneos na MCA do ovo embrionado de galinha. De fato, comparando os resultados do barbatimão com os dos grupos controle negativo e inibidor a diferença foi significativa $(p<0,05)$. Entretanto, quando comparado com o controle indutor, não houve diferença $(p>0,05)$.

A avaliação da atividade angiogênica pelo método da MCA do ovo embrionado de galinha tem sido usada em trabalhos envolvendo plantas medicinais (Melo-Reis et al, 2010, Almeida et al; 2014, Bessa et al, 2015; Araujo et al, 2015).

Na medicina popular o barbatimão possui várias finalidades farmacêuticas descritas na literatura, entre seus principais efeitos medicinais atribuídos a este fitoterápico destaca-se a propriedade cicatrizante (Eurides et al. 1996; Silva 


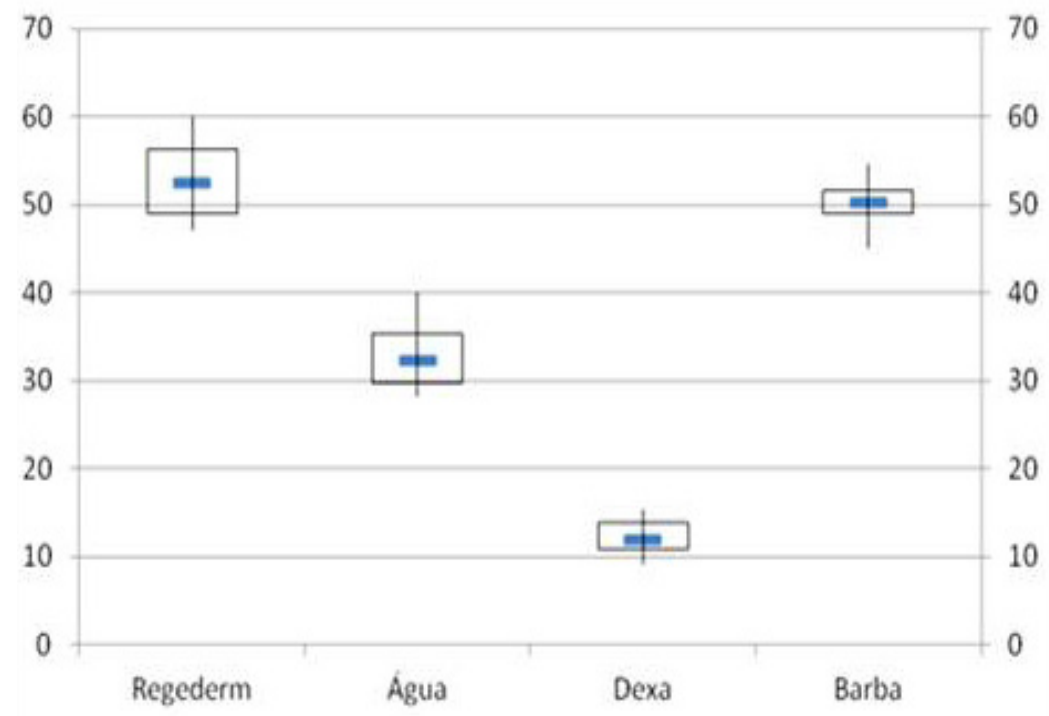

FIGURA 3. Gráfico Boxplot com respectivos valores da MCA após tratamento com a solução aquosa de barbatimão e controles.

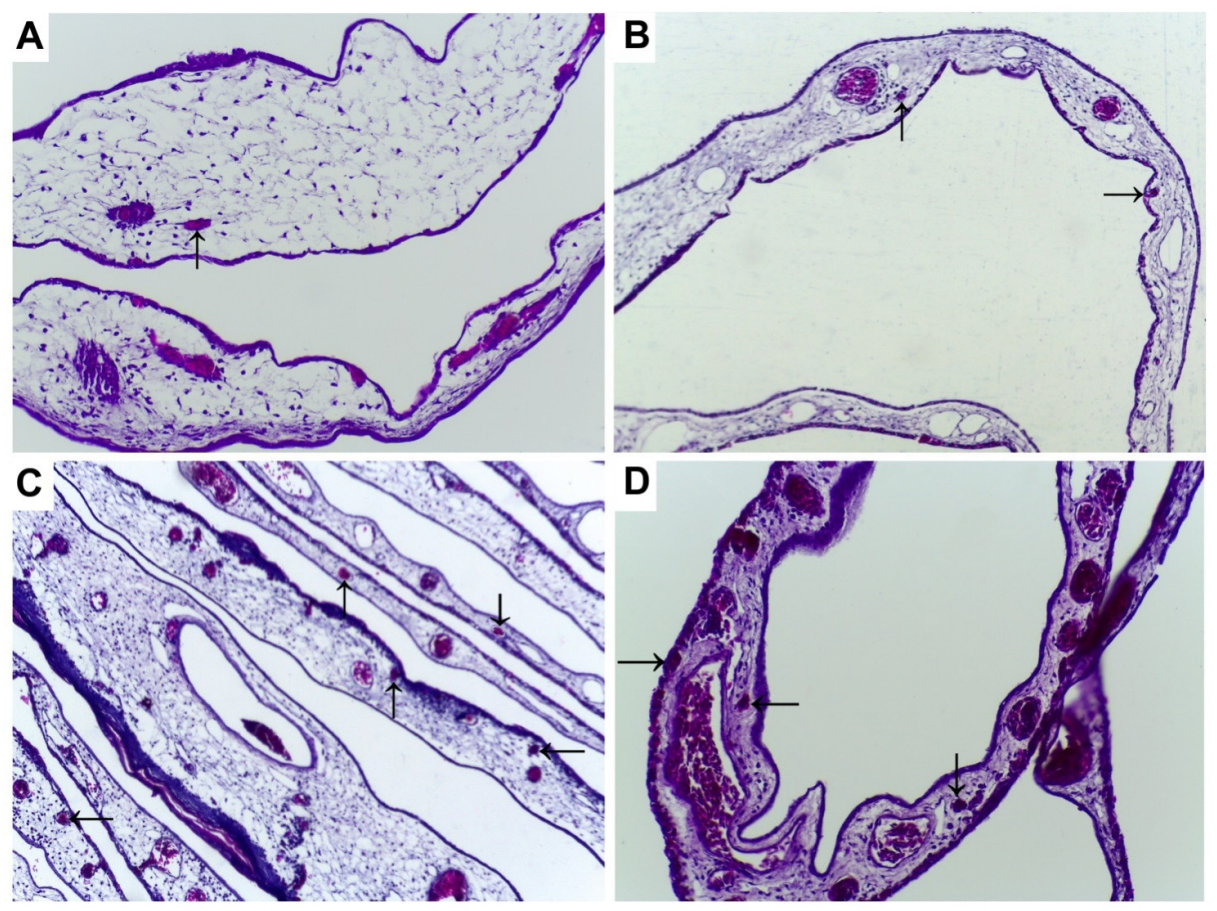

FIGURA 4. Fotomicrografia de Membrana Corioalantóide coradas com hematoxilina-eosina e vistos com objetiva de 20X, apresentando: em (A) o controle inibidor tratado com dexametasona com poucas células do tecido conjuntivo e poucos vasos sanguíneos, em (B) controle negativo (agua destilada), em (C) grupo tratado com Regederm com a presença de angiogenese e elementos inflamatórios e em (D) tratamento com solução aquosa de barbatimão apresentando angiogênese.

et al. 2009; Hernandes et al. 2010; Lima, 2010).O estímulo da angiogênese por fármacos pode ser usado para acelerar a cicatrização e o reparo tecidual promovendo o crescimento de vasos sanguíneos nos tecidos isquêmicos (Heilmann et al. 2002; Detillieux et al. 2003). A característica terapêutica predominante para que o barbatimão seja cicatrizante é atribuída principalmente ao grupo dos taninos condensados, os quais são constituídos por unidades de flavonol: flavan-3-ols (catequina) ou flavan 3,4-diols (leucoantocianidinas). Possui uma estruturação complexa, pode conter de duas a 50 unidades flavonóides, são resistentes a hidrolise, porém podem ser solúveis em solventes orgânicos aquoso, levando em conta a sua estrutura química (Lima, 2010).

O barbatimão já foi testado em vários experimentos cicatrizantes e em diferentes espécies,

Rev. Bras. PI. Med., Campinas, v.18, n.2, p.524-530, 2016. 


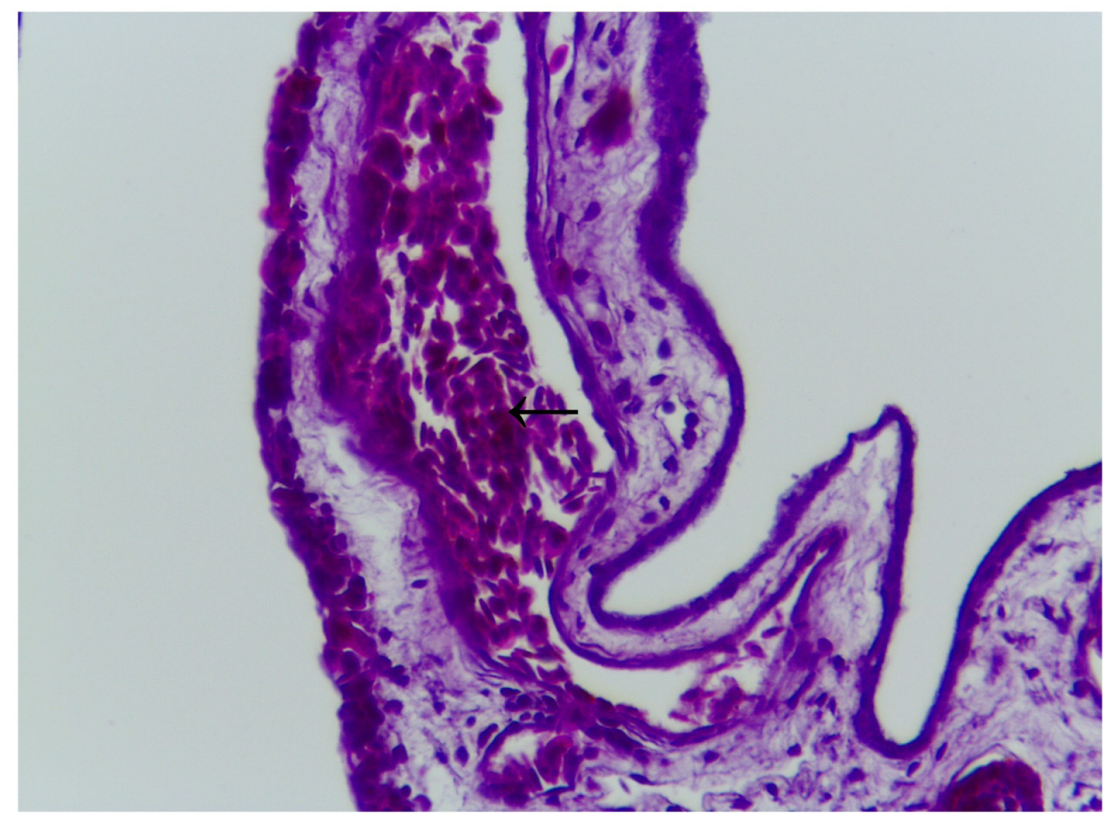

FIGURA 5. Fotomicrografia de membrana corioalantóide tratada com solução aquosa de barbatimão, corada por Hematoxilina \& Eosina, vista com aumento de 40X, apresentando vaso sanguíneo dilatado e elementos inflamatórios no parênquima. A seta indica a presença de eritroblastos.

como, camundongos (Eurides et al. 1996), ratos (Hernandes et al., 2010), coelhos (Lima, 2010), bovinos (Silva et al. 2009), ovinos (Mendonça et al. 2008), cães (Rabelo et al. 2006), gatos (Silva, 2006) e no ser humano (Minatel et al. 2010), por ter atividade angiogênica, comprovada neste trabalho pelo teste da MCA em ovo de galinha.

A cicatrização está relacionada a estímulos angiogênicos (Heilmann et al. 2002; Detillieux et al. 2003). O trabalho comprovou a atividade angiogênica do barbatimão pelo alto índice de vascularização da MCA (Figura 2). Isto explica o porquê de vários trabalhos sobre o barbatimão estão relacionados ao seu poder cicatrizante, entre eles podemos citar: segundo Minatel et al. (2010) em seus estudos em seres humanos, usando no tratamento de úlceras de decúbito em diferentes graus de lesão. No total foram analisados um total de 27 pacientes, total de 51 lesões de decúbito. Os resultados foram satisfatórios, mais de $70 \%$ dos pacientes apresentaram suas feridas totalmente cicatrizadas, onde a área da ferida teve uma redução de $30 \%$ em media, com o tratamento da pomada a $3 \%$ após a primeira semana.

\section{CONCLUSÃO}

Através das condições metodologias aplicadas neste estudo e diante dos resultados obtidos, concluiu-se que a solução aquosa da casca do barbatimão apresenta atividade angiogênica na MCA.

\section{REFERÊNCIA}

ALMEIDA, L.M. et al. Hancoria speciosa latex for biomedical applications: physical and chemical properties, biocompatibility assessment and angiogenic activity. Journal of Materials Science Materials in Medicine, v. 25, n. 9, p. 2153-62, 2014.

ARAUJO, L.A. et al. Angiogenic activity of sucupira (Pterodon emarginatus) oil. Scientia Medica, v. 25, n. 2, p. 1-7, 2015.

BESSA, G. et al. Atividade angiogênica do látex da Euphorbia tirucalli Linnaeus 1753 (Plantae, Euphorbiaceae). Brazilian Journal of Biology, v.75, n.3, p. 752-758, 2015.

BLAAUWGEERS, H.G. et al. Polarized vascular endothelial growth factor secretion byhuman retinal pigment epithelium and localization of vascular endothelial growth factor receptors on the inner choriocapillaris. Evidence for a trophic paracrine relation. American Journal of Pathology, v.155, n. 2, p. 421428, 1999.

DETILLIEUX, K.A. et al.Biological activities of fibroblast growth factor-2 in the adult myocardium. Cardiovascular Research, v.57, p. 8-19, 2003.

EURIDES, D. et al. Morfologia e morfometria da reparação tecidual de feridas cutâneas de camundongos tratadas com solução aquosa de barbatimão (Stryphynodendron barbatiman Martius). Revista da Faculdade de Zootecnia, Veterinária e Agronomia, Uruguaiana, v. 2/3, n. 1, pp. 30-40, 1996.

FOLKMAN, J. The Vascularization of Tumors. Scientific Ameican, v.234, n.5, p.58-64, 1976.

FOLKMAN, J. Tumor angiogenesis: therapeutic implications. New England Journal of Medicine, v.285, p.1182-1186, 1971.

HANAHAN, D.; FOLKMAN, J. Patterns and emerging mechanisms of the angiogenic switch during

Rev. Bras. Pl. Med., Campinas, v.18, n.2, p.524-530, 2016. 
tumorigenesis. Cell, v.86, n.3, p.353, 1996.

HEILMANN, C. et al. Collateral growth: cells arrive at the construction site. Cardiovascular Surgery, v.10, p. 570-578, 2002.

HERNANDES, L. et al. Wound-healing evaluation of ointment from Stryphnodendron adstringens (barbatimão) in rat. Brazilian Journal of Pharmaceutical Sciences, v. 46, n.3, 2010.

JOHNSON, L.V. et al. Activation and inflammatory processes in Drusen formation and age related macular degeneration. Experimental Eye Research, v.73, n.6, p.887-96, 2001.

LIMA, C. R. O. Reparação de feridas cutâneas incisionais em coelhos após o tratamento com barbatimão e quitosana. 2010.104 f. Dissertação (Mestrado em Ciência Animal), Patologia, Clinica e Cirurgia Animal - Escola de Veterinária e Zootecnia, Universidade Federal de Goiás, Goiânia.

MANSUR, P. H. et al. Análise de registros eletrocardiográficos associados ao infarto agudo do miocárdio. Arquivos Brasileiros de Cardiologia, v. 87, n. 2, 2006.

MELO-REIS, P. R. et al. Angiogenic activity of Synadenium umbellatum Pax látex. Brazilian Journal of Biology, v. 70, n. 1, p. 189-194, 2010.

MENDONÇA, G. B. N.; MORAES, J. M.; FERREIRA, J.; LIMA, F. G.; BASTOS, E. R.; SOARES, L. K.; HELOU, J. B.; OLIVEIRAALVES, R.; SILVA, O. C. Laser As-GaAI de baixa potência associado com solução aquosa de barbatimão (Stryphynodendron barbatiman Martius) na reparação tecidual de ferida cutânea séptica de ovino. In: CONGRESSO DE PESQUISA, ENSINO E EXTENSÃO, 5, 2008, Goiânia: UFG, 2008. Versão eletrônica.

MINATEL, D. G. et al. Estudo clínico para validação da eficácia de pomada contendo barbatimão (Stryphnodendron adstringens (Mart.) Coville)* na cicatrização de úlceras de decúbito. Revista Brasileira de Medicina, v. 67, n. 7, 2010.

RABELO, R. E. et al. Uso do barbatimão na cicatrização de feridas cutâneas iatrogênicas em cães. In: CONGRESSO DE PESQUISA, ENSINO E EXTENSÃO DA UFG - CONPEEX, 3, 2006, Goiania: UFG, 2006. Versão eletrônica.

RIBATTI, D. et al. Chorioallantoic membrane capillary bed: a useful target for studying angiogenesis and antiangiogenesis in vivo. The Anatomical record, v. 264, n. 4, p. 317-324, 2001.

SILVA, E. A. O extrato aquoso do barbatimão como cicatrizante em feridas cirúrgicas do tecido cutâneo em gatos. 2006. 34p. Monografia (Especialização - Clínica Médica e Cirúrgica de Pequenos Animais) Patologia e Cirurgia Animal - Universidade Castelo Branco, Campo Grande.

SILVA, L. A. F. et al. Extrato da casca do barbatimão (Stryphnodendron barbatiman Martius) associado ao tratamento cirúrgico e toalete dos cascos na recuperação de bovinos da raça nelore com dermatite digital. Ciência Animal Brasileira, v. 1, p.373-378, 2009.

SILVA, L. A. F.; SILVA, J. A.; LIMA, C. R. O.; DAMBROS, C. E.; CARDOSO, V. S. Uso popular do barbatimão. In: SILVA, L. A. F.; EURIDES, D.; PAULA, J. R.; LIMA, C. R. O.; MOURA, M. I. Manual do Barbatimão. $1^{\circ} \mathrm{ed}$. Goiânia: Kelps, 2010, p.79-85.

SUS, 2014. Lista de plantas medicinais de interesse do SUS (Sistema Único de Saúde). Disponível em: <http://www.plantasmedicinaisefitoterapia.com/ plantas-medicinais-do-sus.html.> Acesso em 22 jul. 2014.

VAN DER SCHAFT, T.L. et al. Early stages of agerelated macular degeneration: an immunofluorescence and electron microscopy study. British Journal of Ophthalmology, v.77, n.10, p.657-61, 1993.

VILE, R. G. Cancer Metastasis: From Mechanisms to Therapies. Chinchester: John Wiley \& Sons, 1995. $210 p, 2^{\circ}$ ed.

WANG, S. et al. Angiogenesis and anti-angiogenesis activity of Chinese medicinal herbal extracts. Life Science, v. 74, p. 2467-2478, 2004. 